кuLTura- мeDia- TeoLogia

ISSN 2081-8971

$2017 \mathrm{nr} 30$, s. 101-121.

\title{
Internetowa aktywność amerykańskiego ruchu alternatywnej prawicy $i$ jej wpływ na radykalizację debaty imigracyjnej w Stanach Zjednoczonych
}

\section{The online activity of the American alternative right movement and its impact on the radicalization of the immigration debate in the United States}

\section{STRESZCZENIE:}

AUTOR ARTYKULU ANALIZUJE WPEYW DYSKURSU

IMIGRACYJNEGO, PROWADZONEGO W MEDIACH INTERNETOWYCH ALTERNATYWNEJ PRAWICY, NA DEBATE NA TEMAT IMIGRACJI W STANACH ZJEDNOCZONYCH. „ALT-RIGHT" JAKO NOWY RUCH SPOŁECZNY POSŁUGUJE SIĘ PODSTAWOWYMI MECHANIZMAMI MEDIALNYMI,

W TYM ZWŁASZCZA ZAGŁUSZANIEM KULTURY, DZIENNIKARSTWEM OBYWATELSKIM ORAZ MOBILIZACJĄ OPARTĄ NA MEDIACH. DZIĘKI NIM KOMUNIKATY ALTERNATYWNEJ PRAWICY PRZENIKAJĄ DO DEBATY PUBLICZNEJ. JEJ RADYKALIZACJĘ W KWESTII IMIGRACJI MOŻNA BYŁO ZAOBSERWOWAĆ PODCZAS PREZYDENCKIEJ

KAMPANII WYBORCZEJ W 2016 R., KIEDY TO MEDIA ALTERNATYWNEJ PRAWICY NA RÓWNI Z MEDIAMI GEÓWNEGO NURTU KSZTAETOWAEY DYSKURS IMIGRACYJNY.

\section{SŁOWA KLUCZOWE:} ALTERNATYWNA PRAWICA, ,ALT-RIGHT”, IMIGRACJA, DYSKURS, NOWE RUCHY SPOŁECZNE

\begin{abstract}
:
THE ARTICLE ANALYZES THE IMPACT OF THE IMMIGRATION DISCOURSE OF THE ONLINE “ALT-RIGHT" MEDIA ON THE DEBATE ON IMMigration In the United STates. The ALTERNATIVE RIGHT, BEING A NEW SOCIAL MOVEMENT, USES FUNDAMENTAL MEDIA GENRES SUCH AS CULTURE JAMMING, CIVIC JOURNALISM AND MOBILIZATION BASED ON THE MEDIA. DUE TO THEM, COMMUNICATIONS ISSUED BY THE ALTERNATIVE MEDIA INFILTRATE INTO THE PUBLIC DEBATE. THE PROCESS OF ITS RADICALIZATION COULD BE OBSERVED DURING THE PRESIDENTIAL CAMPAIGN IN 2016, WHEN THE "ALT-RIGHT" MEDIA, TOGETHER WITH THE MAINSTREAM MEDIA" SHAPED THE US IMMIGRATION DISCOURSE.
\end{abstract}

\section{KEYWORDS:}

ALTERNATIVE RIGHT, ALT-RIGHT, IMMIGRATION, DISCOURSE, NEW SOCIAL MOVEMENTS 


\section{PUBLIC RELATIONS W INSTYTUCJACH NON-PROFIT}

Tednym z głównych tematów podejmowanych podczas kampanii prezydenckiej w Stanach Zjednoczonych w 2016 roku była kwestia imigracji i imigrantów. Inaczej jednak, niż w poprzednich latach, obok środków masowego przekazu zaliczanych do tzw. głównego nurtu, ton debacie publicznej nadawały media alternatywne. Dotyczyło to zwłaszcza mediów związanych z ruchem alternatywnej prawicy. Analizując sondaże opinii publicznej można wręcz stwierdzić, że to właśnie media alternatywne lepiej odczytywały i kształtowały nastroje społeczne, niż te dotychczas uznawane za najważniejsze dla tworzenia politycznego przekazu, a więc „The New York Times” czy „CNN”. Zwycięstwo wyborcze Donalda Trumpa, kandydata najbardziej wyrazistego w kwestii polityki imigracyjnej, a zarazem utożsamianego z ruchem alternatywnej prawicy, jest tego najlepszym przykładem.

Zadaniem niniejszego artykułu jest analiza dyskursu imigracyjnego prowadzonego przez media związane z ruchem ,alt-right” oraz jego wpływu na debatę imigracyjną w Stanach Zjednoczonych. W tym celu przyjęto hipotezę, iż media alternatywnej prawicy, wykorzystując możliwości oferowane im m.in. przez internet, doprowadziły do radykalizacji dyskursu imigracyjnego w USA. Definicja dyskursu została zaczerpnięta z dokonań Normana Fairclougha, który przekonuje, że: „dyskursy nie tylko przedstawiają świat takim, jakim on jest (lub raczej jest postrzegany), lecz także są projekcją, wyobrażeniami, reprezentującymi możliwe światy, które różne są od faktycznego świata i które są związane z projektami, mającymi na celu zmianę świata w konkretnych kierunkach"”.

Podstaw teoretycznych do przeprowadzonych badań dostarczyły teorie funkcjonowania mediów alternatywnych oraz nowych ruchów społecznych. Nie ulega bowiem wątpliwości, że media „alt right” można uznać za alternatywne, zaś sam ruch alternatywnej prawicy wpisuje się w definicję nowych ruchów społecznych (NRS). Z tego też powodu na początku artykułu zostały przybliżone teoretyczne założenia funkcjonowania mediów alternatywnych oraz NRS. Następnie, szerzej omówiono genezę i rozwój amerykańskiej alternatywnej prawicy, a także jej stosunek do imigracji i imigrantów w Stanach Zjednoczonych. Uwzględnienie historii ruchu „alt-right” wydaje się zasadne, zważywszy na wciąż skromny dorobek naukowy poświęcony temu zagadnieniu ${ }^{3}$. Zasadniczą

\footnotetext{
${ }^{1}$ Większość mediów głównego nurtu ostrzegała kandydatów przed zbyt krytycznym stosunkiem do imigracji, jako postawą antagonizującą wyborców wywodzących się z różnych grup etnicznych, co w końcowym rozrachunku okazało się błędem. Por. Ch. Cillizza, How Immigration Could Cripple the Republican Nominee Long Before the 2016 Election, "The Washington Post" 17.07.2015, https://www.washingtonpost.com/news/the-fix/wp/2015/06/17/how-immigration-could-cripple-therepublican-nominee-long-before-the-2016-general-election/?utm_term=.4c34f3c1d6e7, [dostęp: 10.11.2017].

${ }^{2}$ N. Fairclough, Analyzing Discourse. Textual Analysis for Social Research, London 2003, s. 124 (tłumaczenie własne).

${ }^{3}$ Wśród niewielu artykułów i monografii podejmujących temat alternatywnej prawicy w USA i jej aktywności medialnej można wymienić: Media, Culture, and the Religious Right, (red.) L. Kintz, J. Lesage, Minneapolis-London 1998; S. George, Hijacking America. How the Religious and Secular Right Changed What Americans Think, Cambridge 2008; D. Brock, The Republican Noise Machine. Right-Wing Media and How It Corrupts Democracy, New York 2005; J.K. White, Donald Trump and the Scourge of Populism, "The
} 
część artykułu tworzy zaś analiza wpływu mediów związanych z alternatywną prawicą na toczoną w USA debatę imigracyjną. Została ona przeprowadzona przy zastosowaniu podziału na gatunki medialne ${ }^{4}$ właściwe nowym ruchom społecznym; w szczególności chodzić będzie o zagłuszanie kultury, dziennikarstwo obywatelskie oraz mobilizację opartą o media.

\section{Media alternatywne i nowe ruchy społeczne}

Rosnąca popularność amerykańskiej alternatywnej prawicy wynika przede wszystkim z aktywności jej sympatyków w internecie. Zanim więc przybliżona zostanie geneza i rozwój samego ruchu, warto zdefiniować media alternatywne oraz wskazać podstawy teoretyczne ich funkcjonowania. Jak przekonują badacze mediów alternatywnych, sama ich specyfika sprawia, że stworzenie jednej, powszechnej definicji jest niemożliwe. „W pewnym momencie wszystko może stanowić alternatywę czegoś innego" - stwierdza nie bez racji John Downing ${ }^{5}$. Z tego też powodu niektórzy medioznawcy definiują media alternatywne przez pryzmat tego, czym one nie są. I tak, zdaniem brytyjskiej grupy badawczej „Comedia”, media alternatywne „nie są częścią uznanego porządku, nie są też częścią systemu kapitalistycznego, nie przedstawiają poglądów głównego nurtu, w końcu też nie są konwencjonalnym sposobem robienia czegoś” ${ }^{6}$. Większość definicji mediów alternatywnych opiera się bądź na analizie ich statusu prawnego, bądź analizie zawartości, tj. prezentowanych idei, linii programowej itp. W pierwszym przypadku, za media alternatywne uznaje się te, które funkcjonują poza danym porządkiem prawnym, tj. nie są zarejestrowane i nie podlegają stosownym regulacjom. Warto przy tym dodać, że taki wybór nie musi wynikać z kontestacji istniejących reguł przez ich twórców, lecz $\mathrm{z}$ ich amatorskiego, niekomercyjnego charakteru ${ }^{7}$. Z kolei zwolennicy definiowania mediów alternatywnych poprzez prezentowane przez nie poglądy i stanowiska, podkreślają, że to właśnie „pozostawanie w opozycji do głównego nurtu” należy uznać za czynnik konstytuujący ten rodzaj mediów ${ }^{8}$. Tak właśnie media alternatywne charakteryzuje Bar-

\footnotetext{
Forum. A Journal of Applied Research in Contemporary Politics” 2016, vol. 14, issue 3, s. 265-279. Pozostałe artykuły i monografie wykorzystane w niniejszym artykule zostały wykazane w bibliografii.

${ }^{4}$ Warto przy tym podkreślić, że Lievrouw definiuje „gatunek” inaczej, niż to przyjęto w naukach o mediach (tj. podział gatunków dziennikarskich na informacyjne, publicystyczne, pograniczne itp.). Badaczka rozumie go przede wszystkim jako „taktykę medialną”, definiując gatunek jako „,formę ekspresji lub komunikacji, która jest przydatna i/ lub znacząca dla członków danej społeczności w konkretnej sytuacji. Gatunki cechują się zarówno formą, jak i celem. Oznacza to, że posiadają typowe cechy materialne lub wynikają z pewnych konwencji formalnych i umożliwiają ludziom wyrażanie własnych poglądów lub odczuć w celu osiągnięcia zamierzonych celów lub intencji w danej sytuacji. (...) Wydaje się więc, że gatunki są sposobem tworzenia społeczności i kontekstu społecznego oraz kulturowych produktów i kontekstów funkcjonowania". L.A. Lievrouw, Media alternatywne..., dz. cyt., s. 32-34.

${ }^{5}$ J.H. Downing, Radical Media. Rebellious Communication and Social Movements, London 2001, s. ix.

${ }^{6}$ Comedia, The Alternative Press. The Development of Underdevelopment, "Media, Culture and Society" 1984, vol. 6, s. 95.

${ }^{7} \mathrm{Ch}$. Atton, Alternative Media, London-Thousand Oaks-New Delhi 2003, s. 12.

${ }^{8}$ W. Pisarek (red.), Słownik terminologii medialnej, Kraków 2006, s. 173.
} 
tłomiej Golka, według którego wyrażają one „protest, ducha walki określanego na łamach setek pism podziemnych mianem "rewolucji przeciwko ustalonemu porządkowi» w sferze społeczno-ekonomicznej i etycznej"”.

Upowszechnienie dostępu do internetu oraz łatwość, z jaką można zaznaczyć swoją obecność w globalnej sieci, wymusiły modyfikację istniejących definicji mediów alternatywnych. Obecnie większość z nich uwzględnia zarówno model produkcji i funkcjonowania mediów alternatywnych, jak również ich zawartość. Taką właśnie definicję przedstawia Leah A. Lievrouw w książce pt. Media alternatywne i zaangażowanie społeczne. Zdaniem amerykańskiej badaczki, „media alternatywne i zaangażowane wykorzystują lub modyfikują przedmioty, praktyki i ustalenia społeczne służące do komunikacji, przy użyciu technologii informacyjnych i komunikacyjnych w celu zakwestionowania lub zmiany dominujących, powszechnie oczekiwanych lub przyjętych sposobów kreowania życia społecznego, kulturalnego i politycznego" ${ }^{10}$. Oznacza to, że wyznacznikiem „alternatywności” danego medium wcale nie musi być przyjęta przez jego twórców linia polityczna. Media alternatywne mogą bowiem podejmować tematy niezwiązane z bieżącą polityką, a które są pomijane przez tzw. mainstream. Jak bowiem wskazuje John Fiske, cechą konstytutywną mediów alternatywnych jest głównie walka z cenzurą polityczną, gospodarczą, kulturową, religijną itp. ${ }^{11}$

Teorie wyjaśniające funkcjonowanie mediów alternatywnych opierają się głównie na marksistowskich (neomarksistowskich) założeniach, w tym na koncepcji hegemonii kulturowej Antonio Gramsciego i teorii ideologii Louisa Althussera ${ }^{12}$. Na rolę mediów alternatywnych jako przeciwwagi dla „produkcji zgody” zwracali uwagę m.in. Edward S. Herman i Noam Chomsky ${ }^{13}$. Część badaczy, wychodząc z założeń paradygmatu anarchistycznego, uznaje media alternatywne za media uczestniczące (participatory media). Zgodnie z tą teorią, media alternatywne umożliwiają szerokiemu gronu odbiorców współudział we wszystkich etapach produkcji - od pozyskiwania informacji i ich przetworzenia, przez skład i druk, aż po dystrybucję ${ }^{14}$. Media alternatywne pełnią więc rolę tzw. community media, reprezentując głos danej społeczności. Zdaniem Alfonso Dagrona, ,alternatywna forma komunikacji jest w swojej esencji komunikacją uczestniczącą, a alternatywny duch pozostaje tak długo, jak element uczestnictwa nie jest spro-

\footnotetext{
${ }^{9}$ B. Golka, System medialny Stanów Zjednoczonych, Warszawa 2004, s. 206.

${ }^{10}$ L.A. Lievrouw, Media alternatywne i zaangażowanie społeczne, Warszawa 2012, s. 31.

${ }^{11}$ J. Fiske, British Cultural Studies and Television, w: Channels of Discourse. Reassembled, R.C. Allen (red.), London 1992, s. 30-49.

${ }^{12}$ Por. J.B. Gray, Althusser, Ideology, and Theoretical Foundations. Theory and Communication, "Journal of New Media \& Culture" 2005, vol. 3, issue 1, http://www.ibiblio.org/nmediac/winter2004/gray.html [dostęp: 12.12.2017 r.].

${ }^{13}$ E.S. Herman, N. Chomsky, Manufacturing Consent, London 1989.

${ }^{14}$ N. Couldry, Beyond the Hall of Mirrors? Some Theoretical Reflections on the Global Contestation of Media Power, w: Contesting Media Power. Alternative Media in a Networked World, N. Couldry, J. Curran (red.), London 2003, s. 39-54.
} 

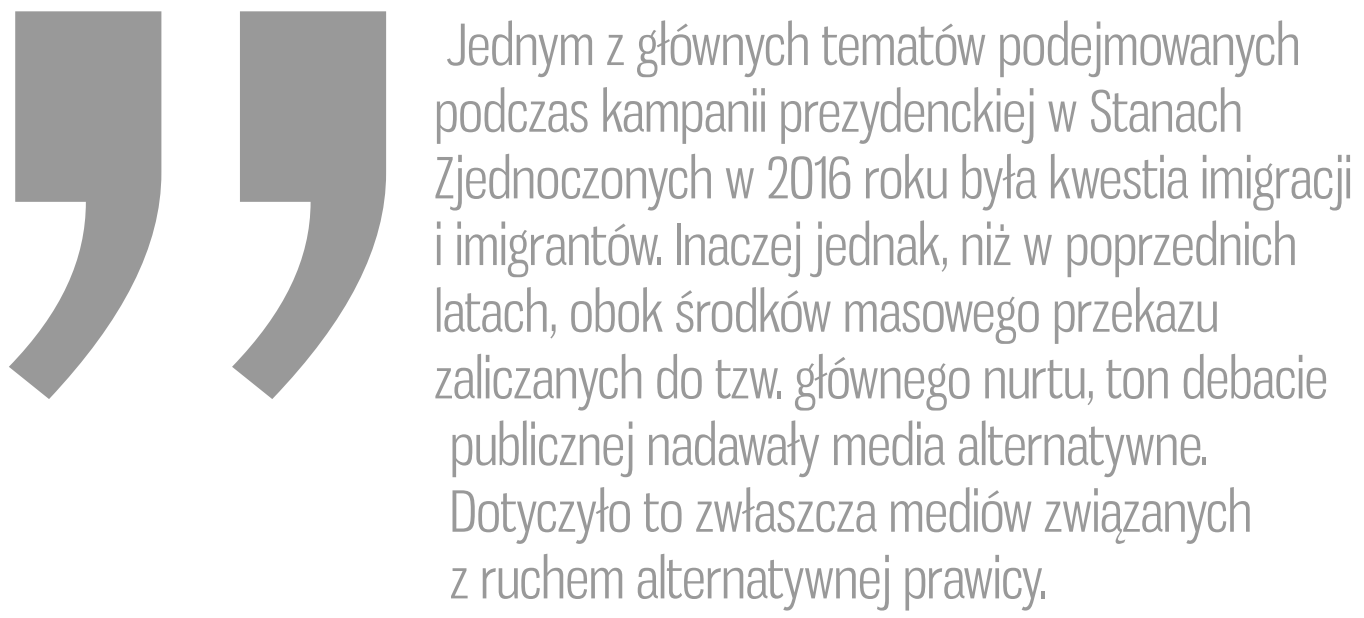

wadzony do minimum lub całkowicie wykluczony"15. Jednocześnie media alternatywne, to media krytyczne, których znaczenie wzrasta w okresach społecznych niepokojów. Powtarzając za Herbertem Marcuse, „rozwój radykalnej politycznej świadomości wśród mas może mieć miejsce jedynie wówczas, kiedy ekonomiczna stabilizacja i społeczna spójność systemu zaczyna się osłabiać" ${ }^{16}$.

Rozwój internetu jeszcze bardziej uwypuklił znaczenie mediów alternatywnych jako mediów uczestniczących i krytycznych. Zdaniem Thomasa Allmera, to właśnie w globalnej sieci „ruchy społeczne są w stanie publikować i rozprowadzać alternatywne poglądy, a także, przy niskich nakładach, podnosić krytyczną świadomość na globalną skalę"17. Coraz powszechniejszy dostęp do internetu oraz łatwość, z jaką można stworzyć własną stronę internetową lub chociażby opublikować opinię sprawia, że tworzy on idealne środowisko dla różnego rodzaju aktywności nowych ruchów społecznych (NRS). Według badaczy i teoretyków NRS, za ich cechy charakterystyczne można uznać kreatywność ich uczestników, zbiorową tożsamość przy jednoczesnej niezależności od instytucjonalnych struktur i kategorii, luźne powiązania i nieformalne struktury, „niekonwencjonalne działania” oraz „kompleksowe, zaawansowane korzystanie z mediów oraz technologii informacyjnej i komunikacyjnej”" ${ }^{18}$. Zdaniem cytowanej już Lievrouw, internetowa działalność nowych ruchów społecznych opiera się na pięciu gatunkach medialnych, tj. zagłuszaniu kultury, komputerowej alternatywie, dziennikarstwie obywatelskim opartym na uczestnictwie, mobilizacji przez media, wspólnych zasobach wiedzy ${ }^{19}$.

\footnotetext{
${ }^{15}$ A.G. Dagron, The Long and Winding Road of Alternative Media, w: The SAGE Handbook of Media Studies, J.H. Downing (red.), London 2004, s. 48.

${ }^{16}$ H. Marcuse, An Essay on Liberation, Boston 1969, s. 54.

${ }^{17}$ T. Allmer, Critical Theory and Social Media. Between emancipation and commodification, London and New York 2015, s. 154.

${ }^{18}$ L.A. Lievrouw, Media alternatywne..., dz. cyt., s. 64-65.

${ }^{19}$ Tamże, s. 36.
} 


\section{Geneza alternatywnej prawicy}

Chociaż tzw. ruch ,alt-right” wzbudza zainteresowanie mediów głównego nurtu od niedawna, jego geneza sięga wielu lat wstecz. Zdaniem konserwatywnych publicystów Richarda A. Viguerie i Davida Franke, początków amerykańskiej alternatywnej prawicy należy szukać już w latach 50. XX wieku, kiedy to media masowe miały zostać zdominowane przez liberalnych sympatyków obu głównych partii politycznych ${ }^{20}$. Tradycyjni konserwatyści poczuli się wówczas zepchnięci na margines. Co prawda ich poglądy były reprezentowane przez niektóre tytuły prasowe, także tzw. prestiżowe (m.in. „The Chicago Tribune”), jednakże nie zdobywały one uznania w debacie ogólnokrajowej. Nie bez racji krytyk literacki Lionel Trilling pisał w 1950 r.: „Obecnie w Stanach Zjednoczonych liberalizm jest nie tylko dominującą, ale wręcz jedyną intelektualną tradycją. Jest bowiem dowiedzione, że w bieżącym powszechnym obiegu zupełnie nie ma konserwatywnych lub reakcyjnych idei" ${ }^{\prime 2}$.

Przełom nastąpił pod koniec lat 90 . XX wieku. Wówczas to pojawiły się pierwsze konserwatywne strony internetowe, na czele z „The Drudge Report”. Założona w 1996 roku przez szerzej nieznanego sprzedawcę z Los Angeles strona www zdobyła popularność dzięki nagłośnieniu romansu prezydenta Billa Clintona ze stażystką Monicą Lewin$\mathrm{sky}^{22}$. Co prawda, większość stołecznych korespondentów wiedziała o skandalu, zdecydowali się jednak oni utrzymać wszystko w tajemnicy, nie chcąc narażać głowy państwa na ataki ze strony przeciwników politycznych. Popularność „The Drudge Report” sprawiła, że na początku XXI wieku niektórzy obserwatorzy uważali go za „,barometr amerykańskiego społeczeństwa”, lecz w dalszych latach jego rozpoznawalność i możliwość wpływania na debatę publiczną znacznie zmalały ${ }^{23}$.

Mimo spadku czytelnictwa „The Drudge Report” tradycyjni konserwatyści coraz śmielej radzili sobie w internecie. Większość z powstałych w pierwszej połowie XXI wieku stron internetowych była niewielkimi, amatorskimi projektami, przypominającymi tradycyjną prasę radykalnej prawicy z lat 20 . i 30 . XX wieku. Z jednej więc strony ich zasięg pozostawał niewielki, z drugiej był wystarczający, aby spełniać funkcje socjalizujące i organizacyjne wśród osób o prawicowych poglądach, a rozczarowanych Partią Republikańską. To właśnie liczne strony, fora czy grupy dyskusyjne doprowadziły do scalenia tego ruchu pod flagą Tea Party. W 2002 roku powstała strona internetowa www.usteaparty.com, która stała się zarzewiem ogólnokrajowego protestu przeciwko reformom społecznym wprowadzonym przez prezydenta George’a W. Busha. Tea Party zarzucała republikańskiej administracji „porzucenie amerykańskich ideałów”, które miało się objawiać m.in. ukróceniem wolności osobistej obywateli oraz zbyt pobłażliwym stosunkiem do nielegalnych imigrantów. Chociaż aż do 2016 roku zwolennicy Tea Party nie

\footnotetext{
${ }^{20}$ R.A. Viguerie, D. Franke, America's Right Turn, Chicago and Los Angeles 2004, s. 75-86.

${ }^{21}$ Cyt. za: R. Kirk, The Conservative Mind. From Burke to Eliot, Washington 2001, s. 476.

${ }^{22}$ Culture Wars in America. An Encyclopedia of Issues, Viewpoints, and Voices, vol. 1-3, w: R. Chapman, J. Ciment (red.), London and New York 2014.

${ }^{23}$ J. Duarte, Futures \& Options, Hoboken 2006, s. 168.
} 
zdobyli dominującej pozycji w Partii Republikańskiej, to kilkudziesięciu kandydatów z jej poparciem dostało się do Kongresu. Jak wskazują niektórzy badacze, aktywność sympatyków alternatywnej prawicy była kluczowa dla odzyskania przez Partię Republikańską większości w Izbie Reprezentantów w 2010 r. Utożsamiający się z nią kongresmeni i senatorzy odegrali ponadto wiodącą rolę $w$ zablokowaniu reform prezydenta Baracka Obamy w 2011 i 2013 roku, czego bezpośrednią konsekwencją był kilkutygodniowy tzw. ,government shutdown”"24.

Tea Party opiera swoją działalność na aktywności swoich szeregowych sympatyków. Nie tylko prowadzą oni strony internetowe, ale także organizują wydarzenia w swoich lokalnych społecznościach oraz prowadzą zbiórki pieniędzy. Zdaniem jednego z komentatorów, ruch ten ,jest mieszaniną oddolnego populizmu, profesjonalnej konserwatywnej polityki oraz wielkich pieniędzy"25. Alternatywna prawica jako ruch społeczny jest niezwykle zróżnicowana. Wśród jej sympatyków znaleźli się bowiem zarówno zwolennicy pomocy socjalnej państwa dla najbiedniejszych, jak i przedsiębiorcy oczekujący powrotu do neoliberalnej polityki gospodarczej epoki Ronalda Reagana. Zdaniem badaczy amerykańskiej sceny politycznej, Tea Party - a w ślad za nią cały ruch alternatywnej prawicy - spajało przede wszystkim poczucie wspólnoty etnicznej. Nie przez przypadek zdecydowana większość sympatyków ruchu rekrutuje się spośród białej części amerykańskiego społeczeństwa. Różni ich zarówno status majątkowy, jak i pozycja społeczna, jednakże łączy obawa przed polityką wielokulturowości, utożsamianą z rosnącą imigracją i liberalizacją praw różnego rodzaju mniejszości, w tym seksualnych ${ }^{26}$. Podobnie, jak większość nowych ruchów społecznych, także alternatywna prawica nie reprezentuje „rozległych, zbiorowych "interesów klasowych" czy ideologii, lecz dąży do wyrażenia swoich subiektywnych doświadczeń i interesów oraz utrzymania swojej niezależności od dominujących instytucji” ${ }^{27}$.

\section{Charakterystyka ruchu ,alt-right”}

Sam termin „,alt-right” funkcjonuje o wiele krócej niż ruch, który opisuje. Po raz pierwszy w publicznym obiegu zaistniał on w 2008 roku, a jego autorstwo przypisuje się Richardowi Spencerowi, konserwatywnemu publicyście, oskarżanemu o rasizm i antysemityzm. Kamieniem węgielnym dla aktywizacji sympatyków ruchu było utworzenie w 2010 roku strony internetowej www.alternativeright.com. Zdaniem Andrew Marant-

\footnotetext{
${ }^{24}$ Por. Ch.S. Parker, M.A. Baretto, Change They Can't Believe in. The Tea Party and Reactionary Politics in America, Princeton 2013.

${ }^{25}$ Ch. Meyer, A New American Revolution? Anti-establishment Tea Party is on the brink of election victories that could leave Obama a lame duck, "Mail Online", 25.10 .2010 [http://www.dailymail.co.uk/news/article1323047/Anti-establishment-Tea-Party-leave-Obama-lame-duck.html [dostęp: 07.12.2017].

${ }^{26}$ R. Willer, M. Feinberg, R. Wetts, Threats to Racial Status Promote Tea Party Support among White Americans, 4 May 2016, SSRN, https://papers.ssrn.com/sol3/papers.cfm?abstract_id=2770186 [dostęp: 08.12.2017]. Por. także: B. Press, Train Wreck. The End of the Conservative Revolution, Hoboken 2008, s. 94-95.

${ }^{27}$ L.A. Lievrow, Media alternatywne..., dz. syt., s. 66 .
} 
za, publicysty prestiżowego „The New Yorker”, termin „alt-right” odnosi się do „luźnych, internetowych powiązań białych nacjonalistów, neo-monarchistów, szowinistów, zwolenników teorii spiskowych, wojujących nihilistów i trolli działających w mediach społecznościowych”28. Z kolei, według konserwatywnego „The National Review”, szeregi alternatywnej prawicy zasilają głównie „zgorzkniali przedstawiciele białej klasy pracującej” ${ }^{29}$. Sami sympatycy alternatywnej prawicy definiują „alt-right” przede wszystkim przez pryzmat sprzeciwu wobec rządów dotychczasowego establishmentu.

W zamieszczonej w internecie w marcu 2016 roku publikacji An Establishment Conservative's Guide to the Alt-Right, Allum Bokhari i Milo Yiannopoulos dowodzą, że ruch ten powstał dzięki wieloletniej internetowej aktywności wielu młodych ludzi, rozczarowanych kierunkiem, w którym zmierzały Stany Zjednoczone. Ich zdaniem wizerunek alternatywnej prawicy jako zbiorowiska „niewykształconych skinów i antysemitów” nie znajduje pokrycia w faktach. „Alternatywną prawicę tworzy grupa niezwykle mądrych ludzi. (...) Są niepokojąco sprytni” - przekonują ${ }^{30}$. Sam ruch ma zaś czerpać z intelektualnych dokonań tak różnych myślicieli, jak Oswald Spengler, H.L. Mencken, Julius Evola i Sam Francis. Tak, jak różnorodne są źródła inspiracji alternatywnej prawicy, tak różnorodni są jej sympatycy. Cytowany przewodnik wymienia takie grupy, jak izolacjoniści, zwolennicy prorosyjskiej polityki, osoby rozczarowane neokonserwatystami, przeciwnicy zaangażowania militarnego USA w świecie, neoreakcjoniści, tradycyjni konserwatyści, a nawet libertarianie ${ }^{31}$.

Cechą wspólną powyższych grup jest ich wysoka aktywność w internecie. Dlatego też Bokhari i Yiannopoulos łączą rosnącą siłę alternatywnej prawicy z „wszechogarniającą cenzurą”, którą utożsamiają z polityczną poprawnością. To właśnie polityczna poprawność miała stać się głównym celem buntu młodego pokolenia: „Młodzi buntownicy przywiązują się do alternatywnej prawicy z tego samego powodu, dla którego pokolenie Baby Boomers fascynowało się Nową Lewicą w latach 60 . XX wieku: ponieważ obiecuje im dobrą zabawę, transgresję oraz kwestionuje normy społeczne, których oni nie rozumieją" ${ }^{2}$. Aktywność alternatywnej prawicy w internecie nie ogranicza się do prowadzenia stron internetowych czy grup dyskusyjnych. Zwolennicy „alt-right” doskonale korzystają z narzędzi oferowanych przez Web 2.0, a więc koncentrują się przede wszystkim na mediach społecznościowych. Krótkie, dosadne komentarze publikowane na Twitterze lub Facebooku mają o wiele większą szansę zaistnienia w ogólnokrajowej debacie, niż długie eseje zamieszczane na niszowych stronach. Jak trafnie zauważył jeden z publicystów brytyjskiego „The Independent”, sympatycy ruchu „powiedzą lub zrobią

\footnotetext{
${ }^{28}$ A. Morowitz, Trolls for Trump, ,The New Yorker” October 31, 2016.

${ }^{29}$ K.D. Williamson, The Father Führer, "The National Review" 2016, vol. LXVIII, no. 5.

${ }^{30}$ A. Bokhari, M. Yiannopoulos, An Establishment Conservative's Guide to the Alt-Right, 29.03.2016, http://www.breitbart.com/tech/2016/03/29/an-establishment-conservatives-guide-to-the-alt-right [dostęp: 08.09.2017].

${ }^{31}$ Tamże.

32 Tamże.
} 
wszystko, aby zaszokować liberalny internet, zdając sobie sprawę, że takie zachowanie zdobywa im popularność wśród rosnącej armii zwolenników składającej się w większości z białych maniaków komputerowych"33. Korzystając z popularnych mediów społecznościowych, zwolennicy alternatywnej prawicy posługują się specjalnym językiem metafor i aluzji, dzięki któremu unikają oskarżeń o rasizm czy antysemityzm. Natomiast bezpośrednim językiem posługują się we własnych mediach, takich jak Gab, stworzony jako nacjonalistyczna alternatywa dla Twittera ${ }^{34}$. Również sympatyzujące $\mathrm{z}$ „alt-right” strony informacyjne, w tym Breitbart News Network (www.breitbart.com), w niczym nie ustępują profesjonalnym serwisom - pozyskują reklamodawców pośród największych firm w Stanach Zjednoczonych ${ }^{35}$. Z tego powodu trudno zatem uznać ten przykład za egzemplifikację „dziennikarstwa obywatelskiego”. Jednakże ze względu na jego linię polityczną - wprost podważającą bieżące fundamenty amerykańskiej polityki oraz modelu funkcjonowania mediów - mieści się on w definicji mediów alternatywnych ${ }^{36}$.

\section{Alternatywna prawica wobec problemu imigracji}

Jak już wcześniej zaznaczono, jednym z elementów spajających różnorodne grupy tworzące wpierw Tea Party, a następnie ruch „alt-right”, jest skrajnie negatywny stosunek do kwestii imigracji. Za symptomatyczne dla całej alternatywnej prawicy można uznać poglądy Patricka J. Buchanana, publicysty i polityka, utożsamianego z tzw. paleokonserwatystami. W swoich licznych książkach i komentarzach od wielu lat przekonuje on, że „największym i najpilniejszym problemem, z którym muszą zmierzyć się Stany Zjednoczone na tej półkuli jest masowa imigracja" ${ }^{37}$. Przy czym, sprzeciw wobec bieżącej imigracji wynika nie tyle z jej rozmiarów, co ze składu etnicznego. Dla Buchanana największe bowiem zagrożenie stanowi zróżnicowanie kulturowe i rasowe setek tysięcy osób przybywających co roku do USA. Nic zatem dziwnego, że w dyskursie imigracyjnym alternatywnej prawicy powracają dobrze już znane elementy, takie jak „niemożność asymilacji” czy „zbyt wielka odmienność kulturowa” niektórych grup ${ }^{38}$. Wszystkie one były

\footnotetext{
${ }^{33}$ D. Walter, How the Alt-Right Invaded Geek Culture, “The Independent” 12.08.2016, http://www.independent.co.uk/voices/how-the-alt-right-invaded-geek-culture-a7214906.html [dostęp: 20.09.2017].

${ }^{34}$ J. Wilson, Gab. Alt-Right's Social Media Alternative Attracts Users Banned from Twitter, "The Guardian” 17.11.2016, https://www.theguardian.com/media/2016/nov/17/gab-alt-right-social-media-twitter [dostęp: 10.12.2017].

${ }^{35}$ D. Ng, Breitbart News Promts More Advertisers, "Los Angeles Times” 7.12.2016, http://www.latimes.com/business/hollywood/la-fi-ct-breitbart-bmw-deutsche-telekom-20161207story.html [dostęp: 10.12.2017].

${ }^{36}$ Również w badaniach prowadzonych przez amerykańskich badaczy dominuje postrzeganie Breitbart News jako medium alternatywnego, odmiennego od „tradycyjnego profesjonalnego dziennikarstwa”. Por. Y. Benkler, R. Faris, H. Roberts, E. Zuckerman, Breitbart-led right-wing media ecosystem altered broader media agenda, "Columbia Journalism Review" 3.03.2017, (https://www.cjr.org/analysis/breitbart-mediatrump-harvard-study.php, [dostęp: 04.03.2017]).

${ }^{37}$ P.J. Buchanan, A Republic, Not an Empire. Reclaiming America's Destiny, Washington 2002, s. 371.

${ }^{38}$ Tenże, Where the Right Went Wrong; New York 2004, s. 257-258.
} 


\section{PUBLIC RELATIONS W INSTYTUCJACH NON-PROFIT}

obecne w amerykańskim dyskursie imigracyjnym co najmniej od połowy XIX wieku, m.in. za sprawą prasy natywistycznej. Z kolei, rosnąca popularność teorii rasistowskich i eugeniki w pierwszych dwóch dekadach XX wieku doprowadziła do przejęcia tych elementów przez prasę prestiżową. W konsekwencji, w latach 1921-1924 przyjęto rozwiązania prawne opierające się na systemie kwot narodowościowych, które zahamowały masową imigrację.

O ile obecnie bezpośrednie odniesienia do rasizmu czy nacjonalizmu pojawiają się w dyskursie alternatywnej prawicy rzadko, to komentarze jej sympatyków w kwestii imigracji i imigrantów można zaliczyć do tzw. rasizmu ukrytego (covert racism). Jak wskazuje Ali Rattansi w swoim Racism. A Very Short Introduction, dyskwalifikacja rasizmu i eugeniki jako teorii całkowicie niezgodnych z nauką sprawiła, że językowa niechęć wobec „innego” wyrażana jest głównie poprzez odniesienia do odmiennej narodowości, kultury czy zwyczajów ${ }^{39}$. Zdaniem Chestera Pierce’a, „ukryte, wynikające z uprzedzenia rasowego decyzje są często ukrywane lub racjonalizowane przez wyjaśnienia, które społeczeństwo jest w stanie zaakceptować" ${ }^{40}$. W przeciwieństwie więc do tradycyjnego rasizmu, otwarcie wyrażanego przez uczestników dyskursu, ukryty rasizm jest trudny do udowodnienia, gdyż odwołuje się do norm, przynależności czy tożsamości danej społeczności. Jako taki, „ukryty rasizm jest często tłumaczony lub mylony z mechanizmami ekskluzji i inkluzji, rytuału i ceremonii, akceptacji i odrzucenia. Ukryty rasizm funkcjonuje jako granica utrzymująca mechanizm, którego głównym celem jest zachowanie społecznego dystansu pomiędzy rasową większością a mniejszościami” ${ }^{* 1}$. Zdając sobie sprawę, że głoszenie otwarcie rasistowskich haseł wykluczyłoby alternatywną prawicę z udziału w debacie publicznej, jej zwolennicy opanowali język metafor i aluzji $\mathrm{w}$ stopniu umożliwiającym im funkcjonowanie w popularnych mediach społecznościowych. Jak już wspomniano, czynią to przede wszystkim poprzez trzy gatunki medialne tożsame dla nowych ruchów społecznych, tj. zagłuszanie kultury, dziennikarstwo obywatelskie oparte na uczestnictwie oraz mobilizację przez media.

\section{Zagłtuszanie kultury}

Według cytowanej wcześniej Lievrouw, zagłuszanie kultury „polega na podchwytywaniu oraz przeinaczaniu obrazów i koncepcji obecnych w mediach głównego nurtu w celu przedstawienia krytycznego komentarza na ich temat" ${ }^{42}$. Innymi słowy, posługujący się tym gatunkiem wykorzystują, przekształcają, a często wręcz zawłaszczają obecne w kulturze masowej symbole, znaki czy technologie w celu krytyki tej kultury. Ważnym aspektem zagłuszania kultury są ironia i żart, które są ,skutecznymi metodami podejmowania dyskusji na temat problemów społecznych, politycznych czy gospodar-

\footnotetext{
${ }^{39}$ A. Rattansi, Racism. A Very Short Introduction, Oxford 2007, s. 87-89.

${ }^{40}$ Ch. Pierce, Offensive Mechanism, w: The Black Seventies, F.B. Barbour (red.), Boston 1970, s. 267.

${ }^{41}$ Introduction, w: Covert Racism. Theories, Institutions, and Experiences, R.D. Coates (red.), Leiden-Boston 2011, s. 2.

${ }^{42}$ L.A. Lievrouw, Media alternatywne..., dz. cyt., s. 94 .
} 

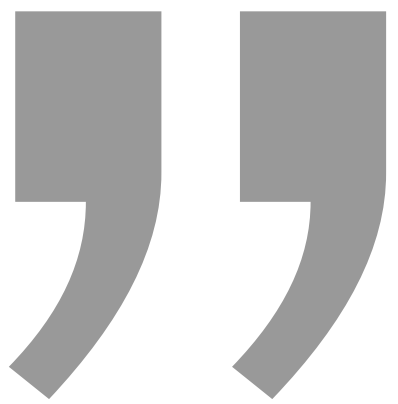

Korzystając z popularnych mediów społecznościowych, zwolennicy alternatywnej prawicy posługują się specjalnym językiem metafor i aluzji, dzięki któremu unikają oskarżeń o rasizm czy antysemityzm. Natomiast bezpośrednim językiem posługująą się we własnych mediach, takich jak Gab, stworzony jako nacjonalistyczna alternatywa dla Twittera.

czych (a nawet obrony idei kojarzonych z nimi), zdobywania zwolenników i zachęcania ich do działania" ${ }^{* 3}$. Przykłady takiego działania można odnaleźć w całej historii ruchów alternatywnych, począwszy od parodii reklam i marek odzieżowych, na tworzeniu fałszywej korporacji skończywszy. Współcześnie zagłuszanie kultury odbywa się m.in. przy wykorzystaniu memów internetowych, zwłaszcza, że stały się one jedną z najważniejszych i najpowszechniejszych jednostek kulturowych, tworzących i upowszechniających idee, symbole i praktyki.

W przypadku alternatywnej prawicy jednym z głównych sposobów zagłuszania kultury jest zawłaszczenie i przekształcenie znanego memu internetowego przedstawiającego żabę Pepe. Postać „Pepe the Frog” stworzył w 2005 roku amerykański artysta Matt Furie, który potrzebował bohatera do swojego niszowego komiksu pt. Boy's Club, opisującego życie współczesnego pokolenia dwudziestolatków ${ }^{44}$. Na przestrzeni kolejnych 11 lat Pepe stał się postacią kultową, zwłaszcza wśród nastolatków. Temu sukcesowi sprzyjało wykorzystywanie tego motywu przez popularne wśród młodego pokolenia gwiazdy muzyki i filmu, takie jak Katy Perry i Nicki Minaj ${ }^{45}$. Niektóre z postów z Pepe the Frog, publikowanych na Instagramie, zdobywały sympatię niemal 300 tys. osób. Proces zawłaszczania postaci przez alternatywną prawicę rozpoczął się w 2015 roku, kiedy to coraz częściej Pepe the Frog był prezentowany z symbolami nazistowskimi i nacjonalistycznymi. Wkrótce też memy z jego udziałem zaczęli powszechnie stosować zwolennicy Donalda Trumpa, wówczas jeszcze jednego z kandydatów w prawyborach prezydenc-

\footnotetext{
${ }^{43}$ Tamże, s. 109.

${ }^{44}$ A. Serwer, It's Not Easy Being Meme, "The Atlantic” 13.09.2016, online:

http://www.theatlantic.com/politics/archive/2016/09/its-not-easy-being-green/499892/ [dostęp: 13.12.2017].

${ }^{45}$ O. Nuzzi, How Pepe the Frog Became a Nazi Trump Supporter and Alt-Right Symbol, "The Daily Beast” 25.05.2016, online: http://www.thedailybeast.com/articles/2016/05/26/how-pepe-the-frog-became-a-nazitrump-supporter-and-alt-right-symbol.html [dostęp:13.12.2017].
} 
kich organizowanych przez Partię Republikańską. Sam Trump użył memu stylizowanego na niego samego ${ }^{46}$. Skala zawłaszczenia memu przez alternatywną prawicę była tak duża, że w 2016 roku The Anti-Defamation League zaliczyła Pepe the Frog do symboli nienawiści, łącznie ze swastyką czy symbolami Ku Klux Klanu ${ }^{47}$.

Do głównych memów z udziałem Pepe the Frog, rozpowszechnianych przez zwolenników alternatywnej prawicy, należą te skierowane przeciwko imigracji i mniejszościom etnicznym. Trudno określić ich dokładną liczbę - podobnie, jak w przypadku innych tego typu tworów, także popularność tego zależy jedynie od wyobraźni internautów. Wśród najczęściej występujących można znaleźć memy prezentujące Pepe stylizowanego na Donalda Trumpa przyglądającego się pozostającej za płotem granicznym meksykańskiej rodzinie, przedstawionej w sposób stereotypowy (mężczyzna jest ubrany w sombrero i ponczo, ma wielkie wąsy). W innym, uśmiechnięty szyderczo i ubrany w hidżab Pepe stoi obok zwłok białej osoby. Istnieje ponadto cała seria memów z Pepe stylizowanym na przedstawicieli różnych nacji - Pepe Żyd, Pepe Arab, Pepe Meksykanin, Pepe Chińczyk. Wszystkie je łączy stereotypowe ukazanie mniejszości - Pepe Żyd ma długi nos, Pepe Meksykanin sumiaste wąsy itp. Towarzyszą im negatywne, choć utrzymane w satyrycznym tonie komentarze. Na przykład pod wizerunkiem Pepe Chińczyka znajduje się napis: „Polub ten mem, albo on zje cały twój ryż”. Jeszcze inne odwołują się do tzw. zdrowego rozsądku. Pepe zadaje pytania dotyczące polityki imigracyjnej, stosunku do muzułmanów czy też poprawności politycznej, a odpowiedź stanowią zamieszczone obok niego zdjęcia, np. samobójczych zamachów, nielegalnych imigrantów czy uzbrojonych islamskich terrorystów.

Powyższe memy rozpowszechniają w internecie nie tylko zwolennicy alternatywnej prawicy. Często robią to nieświadomie inni użytkownicy, w tym nastoletni internauci, którzy nie zauważają antysemickiego czy nacjonalistycznego wydźwięku danego memu. Dla wielu z nich Pepe ustylizowany na Adolfa Hitlera czy żołnierza SS nie niesie za sobą treści ideologicznych, lecz jest jedynie „śmieszny”. Co więcej, część użytkowników postrzega rozpowszechnianie tego rodzaju memów jako sprzeciw wobec „poprawności politycznej”, którą utożsamiają z cenzurą. Jak zauważa w swoim raporcie The AntiDefamation League, „sam fakt zamieszczania memów z Pepe nie oznacza, że ktoś jest rasistą lub zwolennikiem supremacji białych" ${ }^{48}$. Jednak dla zwolenników alternatywnej prawicy przekaz, który niesie Pepe the Frog, jest jednoznaczny. Stał się on nie tylko symbolem ich ruchu, ale także sposobem funkcjonowania w świecie politycznej poprawności, gdzie bezpośrednie nawiązania do rasizmu czy antysemityzmu są wykluczone. Prze-

\footnotetext{
${ }^{46}$ M. Conway, "Pepe the Frog" Creator, Blaming the Election, Tries to Reclaim His Cartoon, "Politico" 13.10.2016, http://www.politico.com/story/2016/10/pepe-the-frog-matt-furie-reclaim-cartoon-229757 [dostęp: 14.11.2017].

${ }^{47}$ L. Westcott, Pepe the Frog Joins Swastika, Burning Cross as Hate Symbol, "Newsweek" 30.09.2016, http://europe.newsweek.com/pepe-frog-hate-symbol-alt-right-503773?rm=eu [dostęp:10.12.2017].

${ }^{48}$ P. Young, Alt-Right Meme Pepe the Frog Branded Hate Symbol by ADL, "Long Island Wins" 06.10.2016, https://longislandwins.com/news/national/alt-right-meme-pepe-frog-branded-hate-symbol-adl/ [dostęp:10.12.2017].
} 

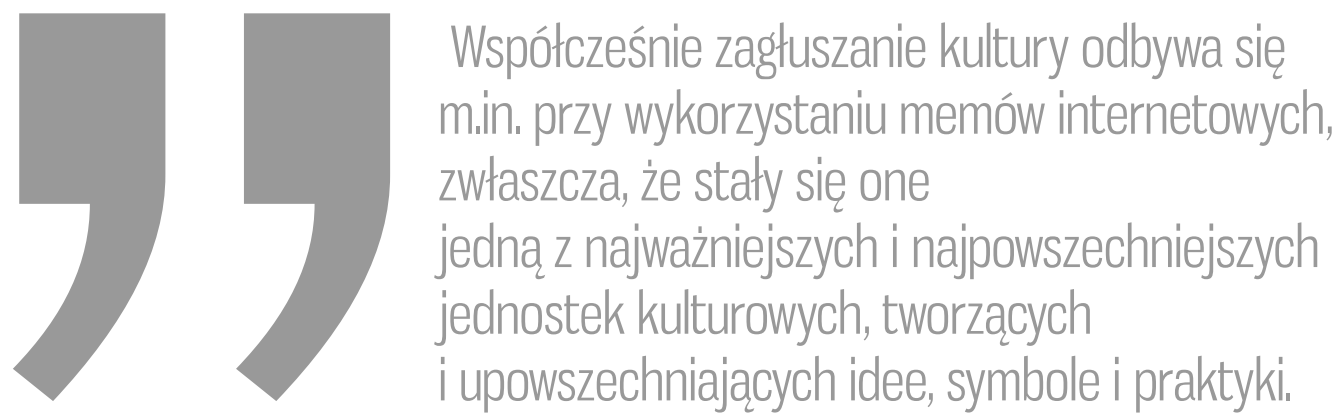

chwytując jeden z najpopularniejszych wytworów kultury masowej, alternatywna prawica doprowadziła do radykalizacji dyskursu, m.in. w kwestii imigracji.

\section{Dziennikarstwo obywatelskie}

Definicje dziennikarstwa obywatelskiego są często tożsame z definicjami mediów alternatywnych. Część badaczy zalicza każdy rodzaj medialnej aktywności obywatelskiej do rodzaju mediów alternatywnych. Podkreślają oni ich amatorski, niezależny charakter, dodając, że ,z jednej strony podtrzymują one tradycyjne wartości oraz praktyki dziennikarstwa czy prasy, a z drugiej wchodzą z nimi w krytyczny dialog"49. Ponadto, dziennikarstwo obywatelskie często podejmuje tematy przemilczane - z różnych powodów przez profesjonalne media. Jednakże, automatyczne uznanie wszystkich form obywatelskiego dziennikarstwa za media alternatywne byłoby nadużyciem. Wiele z amatorskich projektów funkcjonujących w internecie powiela bowiem informacje pozyskane z tradycyjnych mediów. Inne zostają przejęte przez medialne korporacje i tracą swoją niezależność, tak jak to było w przypadku „The Huffington Post” ${ }^{\text {50 }}$. Jeszcze inne jedynie imitują niezależne, amatorskie projekty, faktycznie zaś są finansowane przez potężne przedsiębiorstwa lub grupy interesu.

Podobnych pytań nastręczają projekty medialne związane z ruchem amerykańskiej alternatywnej prawicy. Jak już wspomniano, początków jej wzmożonej internetowej aktywności można doszukiwać się w pierwszych latach XXI w., kiedy to powstało wiele różnego rodzaju stron internetowych, grup dyskusyjnych czy forów, zrzeszających sympatyków „alt-right”. Internet służył im głównie do rozpowszechniania informacji, mobilizacji zwolenników i prezentowania kandydatów do stanowisk politycznych ${ }^{51}$. Przełom nastąpił w roku 2002 wraz z powstaniem strony www.usteaparty.com, która zapoczątkowała proces konsolidacji obecności alternatywnej prawicy w internecie. Jak wy-

\footnotetext{
${ }^{49}$ L.A. Lievrouw, Media alternatywne..., dz. cyt., s. 154.

${ }^{50}$ Por. K. Wasilewski, „The Huffington Post” I “OhmyNews”- analiza porównawcza dwóch globalnych dzienników internetowych, w: A. Jaskiernia, K. Gajlewicz-Korab, Rozwój internetu a zmiany w mediach, systemach medialnych oraz społecznych, Warszawa 2016, s. 347-359.

${ }^{51}$ M. Caiani, L. Parenti, European and American Extreme Right Groups and the Internet, London and New York 2013, s. 108-109.
} 
kazała kampania prezydencka z 2016 roku, ważną pozycję na rynku zajmuje Breitbart News Network (www.breitbart.com), założona w 2007 roku przez konserwatywnego publicystę i przedsiębiorcę Andrew Breitbarta. Po jego śmierci w 2012 roku stroną zaczął zarząazać Stephen Bannon, który nadał jej jeszcze bardziej radykalny charakter ${ }^{52}$. W przeciwieństwie do wielu wcześniejszych projektów, Breitbart News Network prowadzony jest profesjonalnie, zatrudnia dziennikarzy, a nawet korespondentów zagranicznych $^{53}$. Ponadto, jednym z celów funkcjonowania serwisu jest także zysk, stąd obecność na jego łamach reklam. Samo finansowanie Breitbart News, jak również pozostałych tego typu projektów, budzi zastrzeżenia, gdyż za pośrednictwem osób prywatnych de facto wsparcia często udzielają im potężne przedsiębiorstwa. W przypadku niektórych, jak na przykład The Patriot News Agency „stworzonej przez patriotów dla patriotów”, okazało się wręcz, że są to projekty prowadzone i finansowane przez obcokrajowców ${ }^{54}$.

Mimo powyższych wątpliwości faktem jest rosnąca pozycja internetowych serwisów związanych z alternatywną prawicą. Według „Alexa” - witryny mierzącej ruch generowany na stronach internetowych - w listopadzie 2016 roku Breitbart.com plasowal się pod względem liczby unikatowych odwiedzin na 42 pozycji w Stanach Zjednoczonych i 251 na świecie ${ }^{55}$. Dla porównania, w tym samym okresie witryna „The New York Times” zajęła 28 miejsce, a CNN - miejsce 22. Oznacza to, że dysponując o wiele mniejszymi funduszami i rozpoznawalnością, Breitbart.com stał się jednym z ważniejszych źródeł informacji, nie tylko dla zadeklarowanych sympatyków alternatywnej prawicy. Szczyt popularności Breitbart News przypadł na ostatnie tygodnie kampanii prezydenckiej w Stanach Zjednoczonych. Jak wskazuje Google Trends, w tym samym okresie apogeum popularności osiągnęło także zapytanie na temat imigracji ${ }^{56}$. Trudno się temu dziwić, zważywszy, że imigracja stanowiła jeden z najważniejszych problemów dyskutowanych podczas tej kampanii.

Podczas, gdy większość mediów głównego nurtu stara się wskazywać na złożoność tego problemu, podkreślając zarazem humanitarny wymiar polityki imigracyjnej, Breitbart News wraz z pozostałymi witrynami sympatyzującymi z alternatywną prawicą przyjmuje jednoznacznie negatywne stanowisko. Wśród cech charakterystycznych dyskursu imigracyjnego prowadzonego na łamach Breitbart.com, do najważniejszych można zaliczyć przedstawianie imigrantów jako jednolitej masy, koncentrację na negatyw-

\footnotetext{
${ }^{52}$ D. Victor, L. Stack, Stephen Bannon and Breitbart News, in Their Words, "The New York Times" 14.11.2016, (http://www.nytimes.com/2016/11/15/us/politics/stephen-bannon-breitbart-words.html?_r=0 [dostęp:10.12.2017].

${ }^{53}$ J.E. Bromwich, What Is Breitbart News?, “The New York Times” 17.08.2016, http://www.nytimes.com/2016/08/18/business/media/what-is-breitbart-news.html [dostęp: 10.12.2017].

${ }^{54}$ M. McIntire, How a Putin Fan Overseas Pushed Pro-Trump Propaganda to Americans, "The New York Times” 17.12.2016, http://www.nytimes.com/2016/12/17/world/europe/russia-propagandaelections.html?smid=fb-nytimes\&smtyp=cur\&_r=0 [dostęp: 17.12.2017].

${ }^{55}$ Por. http://www.alexa.com/siteinfo/breitbart.com, 16.12.2017.

${ }^{56}$ Por. https://www.google.pl/trends/explore?date=today\%2012-m\&geo=US\&q=immigration [dostęp: 16.10.2017]
} 

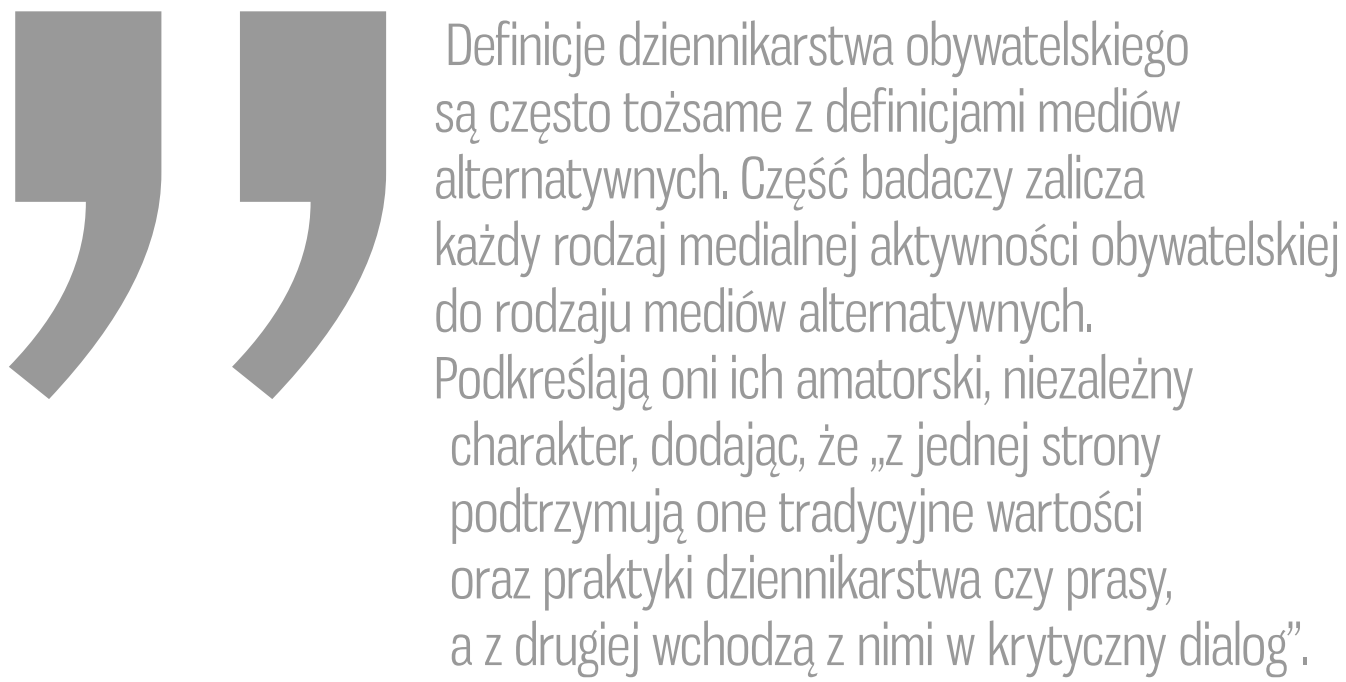

nym aspekcie imigracji oraz powielanie niesprawdzonych, a często wręcz fałszywych informacji. Taki sposób obrazowania imigracji i imigrantów nie jest bynajmniej ograniczony tylko do mediów radykalnej prawicy, lecz funkcjonuje również w niektórych mediach głównego nurtu, jak np. w prasie tabloidowej ${ }^{57}$.

Zwolennicy utrzymania obecnych przepisów imigracyjnych czy tė̇ abolicji dla nielegalnych imigrantów są przedstawiani jako działający na szkodę interesu Stanów Zjednoczonych i całego społeczeństwa. Na przykład dziennikarz Breitbart News powiązał działalność kalifornijskiego oddziału „Amnesty International” przeciwko deportacjom imigrantów z rosnącą przestępczością, podkreślając między innymi, że aktywiści stowarzyszenia chcą ukryć przed władzami federalnymi listy z nazwiskami członków lokalnych gangów ${ }^{58}$. Zdaniem portalu wszelkie doniesienia o pozytywnych aspektach imigracji były jedynie „ideologicznymi mrzonkami mediów głównego nurtu”. Podobnie, osoby opowiadające się przeciwko drastycznemu zaostrzeniu polityki imigracyjnej miały reprezentować bliżej nieokreślone grupy interesów. W trakcie kampanii wyborczej witryna wielokrotnie publikowała sondaże opinii publicznej wskazujące, że większość amerykańskiego społeczeństwa opowiadała się za zaostrzeniem polityki imigracyjnej. Jak przekonywano, takie stanowisko Amerykanów nie mogło dziwić zważywszy, że masowa imigracja była głównym powodem wzrostu bezrobocia, obniżenia płac i „wyparowania amerykańskiego snu" ${ }^{59}$. Ważnym elementem dyskursu imigracyjnego były odpowiednio sformatowane ilustracje, przedstawiające przemiennie imigrantów-przestępców i ubogich amerykańskich obywateli - ofiary wzmożonej imigracji.

\footnotetext{
${ }^{57}$ Por. R. Benson, Shaping Immigration News. A French-American Comparison, New York 2013, s. 4-9.

${ }^{58}$ A. Hawkins, Amnesty Groups Fight to Hide California Gang Database from Trump, "Breitbart News" 06.12.2016, (http://www.breitbart.com/california/2016/12/06/immigrant-groups-want-hide-californiagang-database-trump/ [dostęp: 16.12.2017].

${ }^{59}$ N. Munro, American Dream Evaporates, „Breitbart News” 08.12.2016, (http://www.breitbart.com/biggovernment/2016/12/08/american-dream-sliding-irs-data/ [dostęp: 16.12.2017].
} 
Specyficzny sposób opisywania imigracji przez Breitbart News wpłynął na kształt całego dyskursu imigracyjnego w okresie kampanii prezydenckiej. Po pierwsze, terminy „,imigracja” i „,nielegalna imigracja” zostały ze sobą utożsamione. Chociaż większość publikowanych tekstów dotyczyła obcokrajowców przebywających w USA niezgodnie z prawem, przymiotnik „nielegalny” był stosowany rzadko. Po drugie, materiały dotyczące imigrantów skupiały się głównie na dwóch grupach - Latynosach i muzułmanach. Ta pierwsza grupa stała się synonimem nielegalnego imigranta, przestępcy lub obniżającego standardy płacowe robotnika. Z kolei muzułmanie zostali przedstawieni jako fanatycy religijni, odpowiedzialni za wzrost zagrożenia terrorystycznego. Po trzecie, uprawomocniono pozostające dotychczas na marginesie publicznej debaty fobie związane z „niemożnością asymilacji” czy „różnicami kulturowymi” niektórych grup obcokrajowców.

\section{Mobilizacja przez media}

Jednym z podstawowych celów funkcjonowania mediów alternatywnych jest mobilizacja grup społecznych przeciwko politycznemu, społecznemu czy kulturowemu status quo. O ile tradycyjne media takie, jak prasa czy radio, mają ograniczony zasięg i oddziałują przede wszystkim na osoby już świadome swoich poglądów, o tyle nowe media, w tym zwłaszcza internet, pozwalają uniknąc zagrożenia powstania „,alternatywnego getta"60. Jak trafnie zauważyła Lievrouw, „mobilizacja przez media idzie jednak krok dalej i wykorzystuje nowe media jako narzędzia służące do mobilizowania ruchów społecznych. Polega ona na zbiorowym działaniu, w ramach którego ludzie organizują się i działają razem, będąc aktywnymi uczestnikami zmian społecznych" ${ }^{\circ 1}$. Badaczka podkreśla także, że wielkie, zorganizowane kampanie polityczne skierowane do całego społeczeństwa ustępują obecnie organizowanym ad hoc wydarzeniom odwołującym się do potrzeb określonej grupy społecznej. Może to być protest przeciwko uchwalonej właśnie ustawie lub pojedyncza akcja krytykująca kontrowersyjną wypowiedź lub zachowanie danego polityka. Możliwości oferowane przez nowe media doskonale wykorzystuje amerykańska alternatywna prawica. Ruch Tea Party połączył osoby o różnych poglądach i pozycji społecznej, zebrane początkowo chęcią zmiany najpierw w łonie Partii Republikańskiej, a następnie w całym kraju. Tea Party nie miała zorganizowanych struktur, władz czy nawet oficjalnych członków, a swoje funkcjonowanie opierała niemal wyłącznie na nowych mediach ${ }^{62}$. Stały się one również podstawą kampanii wyborczych wielu polityków związanych z Tea Party, a następnie z ,alt-right”, na czele z Donaldem Trumpem ${ }^{63}$.

\footnotetext{
${ }^{60}$ S. Elghul-Bebawi, The Relationship Between Mainstream and Alternative Media. A Blurring of the Edges?, w: Notions of Community. A Collection of Community Media, J. Gordon (red.), Berlin 2011, s. 22.

${ }^{61}$ L.A. Lievrouw, Media alternatywne..., dz. cyt., s. 190.

${ }^{62}$ D. Karpf, The MoveOn Effect. The Unexpected Transformation of American Political Advocacy, New York 2012, s. 135-138.

${ }^{63}$ K. Lockhart, Why Social Media is Donald Trump's most powerful weapon, “The Telegraph” 22.09.2016, (http://www.telegraph.co.uk/news/2016/09/22/watch-why-social-media-is-donald-trumps-most-powerfulweapon/, 10.12.2017).
} 

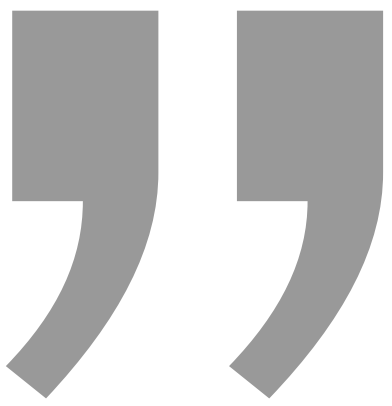

\section{Media alternatywnej prawicy odegrały istotną rolę w mobilizacji}

jej sympatyków przeciwko imigrantom i imigracji.

W czasie ostatniej kampanii prezydenckiej liczne strony internetowe i fora służyły

m.in. do angażowania użytkowników - zarówno w sieci, jak i w świecie realnym - do wyrażenia swojego niezadowolenia z dotychczasowej polityki imigracyjnej rządu federalnego.

W pierwszym przypadku agresywna publicystyka witryn internetowych związanych z alternatywna prawicą uaktywniała użytkowników do wyrażenia swojej opiniil w mediach społecznościowych.

Media alternatywnej prawicy odegrały istotną rolę w mobilizacji jej sympatyków przeciwko imigrantom i imigracji. W czasie ostatniej kampanii prezydenckiej liczne strony internetowe i fora służyły m.in. do angażowania użytkowników - zarówno w sieci, jak i w świecie realnym - do wyrażenia swojego niezadowolenia z dotychczasowej polityki imigracyjnej rządu federalnego. W pierwszym przypadku agresywna publicystyka witryn internetowych związanych z alternatywną prawicą uaktywniała użytkowników do wyrażenia swojej opinii w mediach społecznościowych. Przez cały rok 2016 Facebook czy Twitter doświadczały zmasowanych kampanii sympatyków ,alt-right” wypowiadających się przeciwko imigracji i imigrantom $^{64}$. Jak wskazuje publicystka Amelia Tait, poglądy wyrażane w internecie znajdowały bezpośrednie odniesienie w programach wyborczych: „Zamiast polegać na publicznych spotkaniach, kandydaci mogą dowiedzieć się o opiniach wyborców - i odpowiednio dostosować swój program - w czasie rzeczywistym”65. Jednocześnie - jak już wspomniano - zwolennicy alternatywnej prawicy potrafili wypracować specjalny język metafor i symboli, dzięki któremu ich radykalne poglądy mogły zaistnieć w ogólnodostępnych serwisach.

Media alternatywnej prawicy mobilizowały zarazem swoich sympatyków do akcji realizowanych w „świecie realnym”. Można było to zaobserwować podczas kam-

\footnotetext{
${ }^{64}$ A. Tait, Control, Alt-Right, Retweet: How Social Media Paved the Way for President Trump, “The New Statesman" 10.11.2016, (http://www.newstatesman.com/world/north-america/2016/11/control-alt-rightretweet-how-social-media-paved-way-president-trump [dostęp: 11.12.2017].

${ }^{65}$ Tamże.
} 
panii prezydenckiej Donalda Trumpa, kiedy to często jednego dnia spotykał się on z mieszkańcami kilku miejscowości, znajdujących się nierzadko w różnych stanach. Tradycyjne sposoby komunikacji, jak prasa czy działalność przedstawicieli wyborczych, nie byłyby w stanie sprostać takiemu wyzwaniu. Ponadto, w trakcie takich wieców zwolennicy Trumpa deklarowali swój sprzeciw wobec dotychczasowej polityki imigracyjnej rządu federalnego; sprzeciw, którego podstawą były informacje i opinie publikowane przez Breitbart News i pozostałe tytuły związane z alternatywną prawica. Jak wykazały badania opinii publicznej przeprowadzone w sierpniu 2016 r. przez Pew Research Center, dla 66 proc. osób deklarujących poparcie dla Donalda Trumpa kwestia imigracji stanowiła priorytet, ważniejszy nawet od terroryzmu. Dla porównania, zaledwie 17 proc. zwolenników Hillary Clinton było podobnego zdania ${ }^{66}$. Co więcej, w tej pierwszej grupie niemal 80 proc. badanych za najskuteczniejszy sposób walki z nielegalną imigracją uważało budowę muru na granicy z Meksykiem ${ }^{67}$. Nie przez przypadek mur graniczny stał się słowem-kluczem w całej antyimigranckiej kampanii prowadzonej przez media alternatywnej prawicy.

\section{Podsumowanie}

Wraz ze zwycięstwem Donalda Trumpa w wyborach prezydenckich w 2016 r., ruch alternatywnej prawicy zyskał powszechne zainteresowanie mediów - amerykańskich i zagranicznych. Warto jednak podkreślić, że nie powstał on w próżni, lecz jako nowy ruch społeczny budował swoją pozycję w globalnej sieci już od początku XXI wieku. W międzyczasie liczne blogi, fora i grupy dyskusyjne, zakładane przez amatorów, zostały uzupełnione w branży o profesjonalne serwisy informacyjne i publicystyczne, takie jak na przykład Breitbart News. Wszystkie one umożliwiły zwolennikom alternatywnej prawicy aktywne kwestionowanie politycznego, społecznego i kulturowego status quo wStanach Zjednoczonych.

Podobnie, jak w przypadku każdego nowego ruchu społecznego, w szeregach alternatywnej prawicy znajdują się osoby o różnym wykształceniu, statusie społecznym, a nawet światopoglądzie. Jednym z głównych elementów łączących wszystkich sympatyków „alt-right” jest natomiast krytyka obecnej polityki imigracyjnej USA i niechęć wobec imigrantów w ogóle. Dążąc do zmiany akcentów w debacie publicznej na temat imigracji, zwolennicy alternatywnej prawicy posługują się różnymi gatunkami medialnymi, w tym przede wszystkim - przybliżonymi powyżej - zagłuszaniem kultury, dziennikarstwem obywatelskim oraz mobilizacją przez nowe media. Pozostałe, a więc hackerstwo i wspólne zasoby wiedzy, w przypadku debaty imigracyjnej odgrywają poślednią rolę, choć - co należy podkreślić - są sympatykom „alt-right” dobrze znane. Upublicznienie korespondencji Narodowego Komitetu Partii Demokratycznej, czy wykorzystanie WikiLeaks w celu dyskredytacji przeciwników po-

\footnotetext{
${ }^{66}$ J. Boccagno, Immigration Remains Top Concern for Trump Supporters, “CBS News”, 26.08.2016, http://www.cbsnews.com/news/poll-immigration-donald-trump-supporters/ [dostęp: 14.12.2017].

${ }^{67}$ Tamże.
} 
litycznych, to tylko dwa z wielu potwierdzających to przykładów ${ }^{68}$. Tymczasem przejmując i przekształcając produkty kultury masowej, bądź też wprowadzając do mediów społecznościowych fałszywe informacje, zwolennicy amerykańskiej alternatywnej prawicy stopniowo radykalizują debatę publiczną na temat imigracji. Tworzenie popularnych memów propagujących nacjonalistyczne i rasistowskie hasła czy zawłaszczenie serwisów społecznościowych umożliwiło włączenie do publicznego obiegu poglądów skrajnych i do tej pory marginalizowanych. Za zasadną można tym samym uznać tezę postawioną na początku niniejszego artykułu, że media alternatywnej prawicy, wykorzystując możliwości oferowane im m.in. przez internet, doprowadziły do radykalizacji dyskursu imigracyjnego w USA.

\section{BIBLIOGRAFIA}

Allmer T., Critical Theory and Social Media. Between emancipation and commodification, London and New York 2015.

Atton Ch., Alternative Media, London-Thousand Oaks-New Delhi 2003.

Benkler Y., Faris R., Roberts H., Zuckerman E., Breitbart-led right-wing media ecosystem altered broader media agenda, "Columbia Journalism Review" 3.03.2017, https://www.cjr.org/analysis/breitbart-media-trump-harvard-study.php [dostęp: 04.12.2017].

Benson B., Shaping Immigration News. A French-American Comparison, New York 2013.

Bokhari A., M. Yiannopoulos, An Establishment Conservative's Guide to the Alt-Right, 29.03.2016, http://www.breitbart.com/tech/2016/03/29/an-establishment-conservatives-guide-to-the-alt-right [dostęp: 08.09.2017 r.].

Buchanan P.J., A Republic, Not an Empire. Reclaiming America's Destiny, Washington 2002.

Buchanan P.J., Where the Right Went Wrong; New York 2004.

Caiani M., Parenti L., European and American Extreme Right Groups and the Internet, London and New York 2013.

Ch. Meyer, A New American Revolution? Anti-establishment Tea Party is on the brink of election victories that could leave Obama a lame duck, "Mail Online", 25.10.2010, http://www.dailymail.co.uk/news/article1323047/Anti-establishment-Tea-Party-leave-Obama-lame-duck.html [dostęp: 07.12.2017 r.].

Cillizza Ch., How Immigration Could Cripple the Republican Nominee Long Before the 2016 Election, "The Washington Post" 17.07.2015, https://www.washingtonpost.com/news/the-fix/wp/2015/06/17/how-immigration-could-cripple-the-republican-nominee-long-before-

\footnotetext{
${ }^{68}$ Por. R. Dimanno, Julian Assange now the hero of the alt-right, “The Toronto Star" 15.11.2016, https://www.thestar.com/news/gta/2016/11/15/julian-assange-now-the-hero-of-the-alt-rightdimanno.html [dostęp: 12.12.2017 r.].
} 
-the-2016-general-election/?utm_term=.4c34f3c1d6e7 [dostęp: 10.11.2017 r.].

Comedia, The Alternative Press. The Development of Underdevelopment, "Media, Culture and Society" 1984, vol. 6, s. 95-102.

Couldry N., Beyond the Hall of Mirrors? Some Theoretical Reflections on the Global Contestation of Media Power. W: Contesting Media Power. Alternative Media in a Networked World, N. Couldry, J. Curran (red.), London 2003.

Culture Wars in America. An Encyclopedia of Issues, Viewpoints, and Voices, vol. 1-3, R. Chapman, J. Ciment (red.), London and New York 2014.

Dagron A.G., The Long and Winding Road of Alternative Media, w: The SAGE Handbook of Media Studies, J.H. Downing (red.), London 2004.

Downing J.H., Radical Media. Rebellious Communication and Social Movements, London 2001.

Duarte J., Futures \& Options, Hoboken 2006.

Fairclough N., Analyzing Discourse. Textual Analysis for Social Research, London 2003.

Fiske J., British Cultural Studies and Television. W: Channels of Discourse. Reassembled, R.C. Allen (red.), London 1992.

Golka B., System medialny Stanów Zjednoczonych, Warszawa 2004.

Herman E.S., Chomsky N., Manufacturing Consent, London 1989.

Introduction, w: Covert Racism. Theories, Institutions, and Experiences, R.D. Coates (red.), Leiden-Boston 2011.

Karpf D., The MoveOn Effect. The Unexpected Transformation of American Political Advocacy, New York 2012.

Kirk R., The Conservative Mind. From Burke to Eliot, Washington 2001.

Lievrouw L.A., Media alternatywne i zaangażowanie społeczne, Warszawa 2012.

Marcuse H., An Essay on Liberation, Boston 1969.

Morowitz A., Trolls for Trump, „The New Yorker”, 31.10.2016, http://www.newyorker.com/magazine/2016/10/31/trolls-for-trump [dostęp: 10.11.2017 r.].

Parker Ch.S., Baretto M.A., Change They Can't Believe in. The Tea Party and Reactionary Politics in America, Princeton 2013.

Pierce Ch., Offensive Mechanism, w: The Black Seventies, F.B. Barbour (red.), Boston 1970.

Pisarek W. (red.), Słownik terminologii medialnej, Kraków 2006.

Press B., Train Wreck. The End of the Conservative Revolution, Hoboken 2008.

Rattansi A., Racism. A Very Short Introduction, Oxford 2007.

Viguerie R.A., Franke D., America's Right Turn, Chicago and Los Angeles 2004. 
Wasilewski K., „,The Huffington Post” I “OhmyNews” - analiza porównawcza dwóch globalnych dzienników internetowych, w: A. Jaskiernia, K. Gajlewicz-Korab, Rozwój internetu a zmiany w mediach, systemach medialnych oraz społecznych, Warszawa 2016, s. 347-359.

Williamson K.D., The Father Führer, "The National Review” 2016, vol. LXVIII, no. 5 .

\section{OAUTORZE:}

Krzysztof Wasilewski - dr nauk humanistycznych, historyk i medioznawca, pracownik naukowy Wojewódzkiej i Miejskiej Biblioteki Publicznej im. Zbigniewa Herberta w Gorzowie Wielkopolskim; zainteresowania badawcze: media alternatywne, framing; komunikowanie międzykulturowe, analiza dyskursów migracyjnych; KONTAKT: krzys.wasilewski@gmail.com. 